\title{
Teaching and Learning with Pictures the Use of Photography in Primary Schools ${ }^{+}$
}

\author{
Serena Triacca \\ Catholic University of the Sacred Heart, CREMIT (Research Center about Education, Media, Information and \\ Technology), 20123 Milan, Italy; serena.triacca@unicatt.it \\ + Presented at the International and Interdisciplinary Conference IMMAGINI? Image and Imagination \\ between Representation, Communication, Education and Psychology, Brixen, Italy, 27-28 November 2017.
}

Published: 10 November 2017

\begin{abstract}
Considering the relevance of images in the teaching and learning process, through four case studies we aimed to explore the actual use of photography in Primary School. Starting from the pedagogical reflections about the cases, the research intends to increase the educational research's awareness about the use of photographic images in the classroom.
\end{abstract}

Keywords: image based technologies for teaching and learning; photography

\section{Introduction}

Teachers usually adopt visuals to support oral presentations, to make the concepts clear and situated, to facilitate focusing on relevant elements. To support the mediation process [1], they often draws on a representational repertoire [2].

There are many studies about the impact of digital images and text on learning: Calvani [3] and Paoletti [4] state that if everyone agrees on the need of adopting images to support remembering and learning, on the other side we are not always aware of the difficulty of understanding them. International scholars [5] identifies specific visuals' functions (communicative and psychological); principles of Multimedia Learning [6] and the Theory of Cognitive Load [7], which consider the crucial role of the image in understanding oral and written text, are well known.

Many research-action's projects about digital devices at school, run by CREMIT (Research Center about Education, Media, Information and Technology) based at Catholic University of Milan, highlight that presenting and representing, designing and showing learning objects on the screens of different devices, are the most used technological features [8,9].

Therefore, using images in teaching practices is a need, an opportunity and a challenge for the modern teacher: a need, since the language of the image must have full citizenship on the special "cognitive keyboard" [10] consisting of the complex of different languages; an opportunity, since in the educational design process [11], teacher can wonder systematically about his own practices and pay attention to the information retrieval, testing quality and effectiveness of the resources; teachers can be active and responsible makers of digital learning images.

The lens with which we have tried to approach the problem is that of neuroscience. Rivoltella [10] suggests that the trajectories of neuroscience and didactics can converge: contributions about the peculiarity of the visual brain [12] and the body's value in aesthetic experience [13] can be interesting for the teacher, already used to employ images widely, but not always consciously, in the mediation process. Providing the learners with a graphic or iconic representation supports brain work, normally engaged in a search for the essentials within the flow of the world, scaffolding the learner to work on a simplified scenario.

Our field of research focuses on photographic images: they are easy to take, manipulable objects, thanks to digital convergence the contents are transmedial; Internet of Things (IoT) lets us post a 
photo taken with a smartphone on Instagram or send it to a Whatsapp group. These featurescommon to all cultural objects produced by digital media - have led us to reflect on the didactic value of the photographic image, on consuming and taking photographs in the classroom.

Photographs would be special in "opening the way" rather than reducing the cognitive and semantic ambiguity. Such ambiguity, or "the certainty of a number of possible interpretations" [14], could be exploited by the teacher.

The teacher's role is to guide the learners to deep understanding [15] and one way in which images support brain work is concepts visualization.

Photography:

- provides understanding of "advantageous access points": through images, it is possible to play with the "WOW" effect, or to use them with the intent of "stitching", to intrigue, to activate interest. Let's think about special pictures, with unusual prospective or that represent situations far from children's field of experience (unknown places and characters, shrinking or magnified objects ...);

- activates associations and analogies: through known situations or subject photographs, it is possible to understand what is unknown, urging perceptual stimulation;

- stress the emotional encoding role [16]: for this purpose, photographs of movements and emotions can be used to portray pupils in activities, those taken in the contexts of life known to children (school, park, house) or as part of an educational trip or, more generally, photos of people. We know the other people are special for us, since that in our brains there are two specific areas dedicated to recognizing bodies and faces.

The potential of photography, rather than being related to the mere reproduction of reality, is closely related to its ambiguity and its excess of meaning [17], its ability to "sting" or "shake" [18], to invoke deduction, speculation and fantasy [19].

\section{Materials and Methods}

In the two-stage research plan several tools has been developed (Table 1) the aim was to focus on the educational practices about the use of photography in the Primary School context.

Table 1. Research plan.

\begin{tabular}{|c|c|c|c|c|}
\hline Phase & Research Tool & Subject & Goals & $\mathbf{N}$. \\
\hline 1 & Questionnaire & Teachers & Exploring frequency and use of different kind of images & 460 \\
\hline 2 & Teacher's Diary & Teachers & Lesson planning & 4 \\
\hline 2 & Video-research & $\begin{array}{l}\text { Teachers, } \\
\text { students }\end{array}$ & Observing lessons & 8 \\
\hline 2 & Interview & $\begin{array}{c}\text { Teachers, } \\
\text { expert }\end{array}$ & Collecting perceptions about the experience and its implications & 5 \\
\hline 2 & Focus group & Students & Collecting perceptions about the experience and its implications & 2 \\
\hline
\end{tabular}

In the first phase of the study an online exploratory questionnaire about the educational use of visuals was administered to K-12 teachers.

Data were read with the aim of focusing on representations and orientations of use, deeper into a subsequent qualitative field research. Four case studies [20] have been selected, each associated with a user profile related to a schema, validated in an international research on the use of moving images in training contexts [21,22] (Figure 1). 


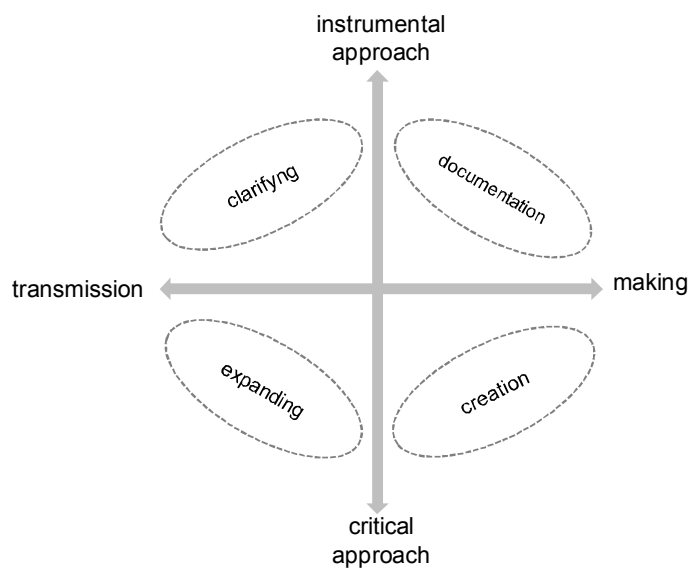

Figure 1. The first axis, the vertical one, intends to return the pedagogical approach, assuming a practices range moving from the instrumental use of pictures in didactics to the critical use. The second axis, the horizontal one, refers to didactic and includes as extreme points the didactical paradigm of transmission and making. Axis intersection generates four emerging profiles.

Four teachers, stating that they frequently used pictures in class, were each assigned to a profile of use. In the case of study, we intended to find out which types of lessons-activities were designed using (or making) photographic images; the reasons behind the choice of different images; the educational relevance of the proposed images, in relation to the planned lesson plans and the assigned user profile.

\section{Results}

\subsection{Cases "Transmission/Instrumental" and "Making/Critical"}

In Table 2, we provide some information on the context of the four cases. In this section we focus on "transmission_instrumental" (T_I) and "making_critical" (M_C) profiles.

Table 2. Contexts of the cases.

\begin{tabular}{ccccc}
\hline & T_I & M_C & M_I & T_C \\
\hline Class & $1^{\circ}$ & $5^{\circ}$ & $2^{\circ}$ & $5^{\circ}$ \\
N $^{\circ}$ students & 15 & 19 & 26 & 18 \\
Special needs students & 0 & 2 & 0 & 0 \\
LIM in class & yes & no & no & no \\
LIM in laboratory & no & yes & yes & yes \\
Laboratory & yes & yes & yes & yes \\
BYOD & yes & yes & yes & yes \\
\hline
\end{tabular}

In T_I case, all lessons refer mainly to the historical-social axis (history, geography) and the languages axis (italian, image, technology). Even though you are concerned with the lecture format, lessons are based on conversation (heuristic lessons). In many lessons the teacher personally took pictures to support them. In each case, a set of images that were specially made or assembled through Web research was used in each lesson.

Interactive White Board (IWB) is a common support for displaying images and short texts and surfing the Web or as an interactive surface that allows editing and manipulating objects. The teacher took great care in archiving the didactic materials produced, even in view of possible reuse in subsequent lessons. In almost all cases, the photos were also printed to be glued to children's notebooks. Textbooks have never been used.

Images have been proposed in different activities: 
- chronologically ordering an experience;

- detecting changes over time in animated objects and subjects;

- rebuild a route on the territory;

- understanding the cyclical trend of the seasons;

- image analysis and writing a short text.

Teachers state that photographs helped simplifying concepts and have had a decisive impact on learning.

In the M_C case, "La fabbrica delle storie" laboratory project involved directly a professional photographer and three class teachers. It should be emphasized that children, from the third class, have been involved in photographic language projects.

Photography was used for storytelling. After watching Shrek, the children analyzed structure and characters, getting to know the Propp Cards and writing in pairs an original fairy tale. Three sequences have been extracted from the text, storyboards and scenographies were made. For each stage, the children have made a session of shots, with the stop motion technique (150-300 shots per sequence). Couples were constantly supported by the expert. After the photographic sessions, children produced the audio narrative. In the garden they made photographs for the video covers. The activity ended with photo and audio editing phase, with the introduction of textual parts and soundtracks by the expert, in order to create an iPad app (Figure 2).

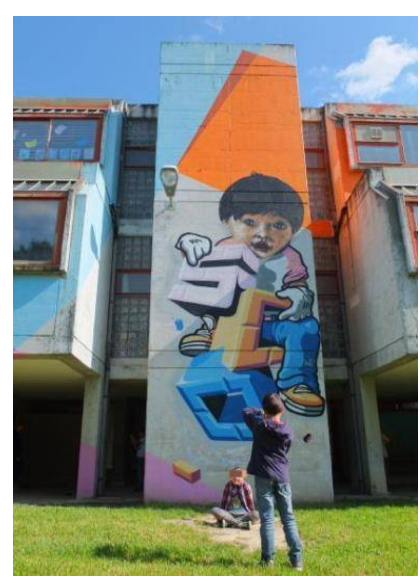

(a)

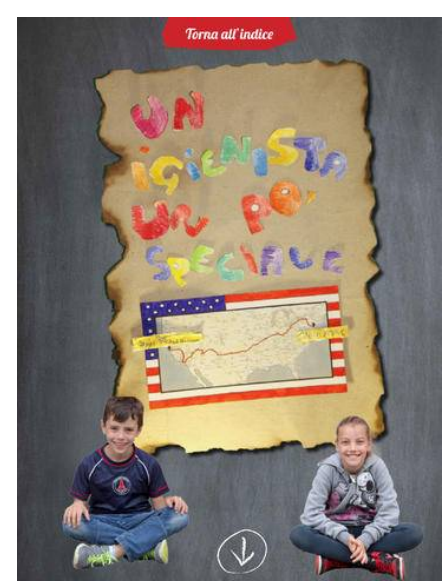

(b)

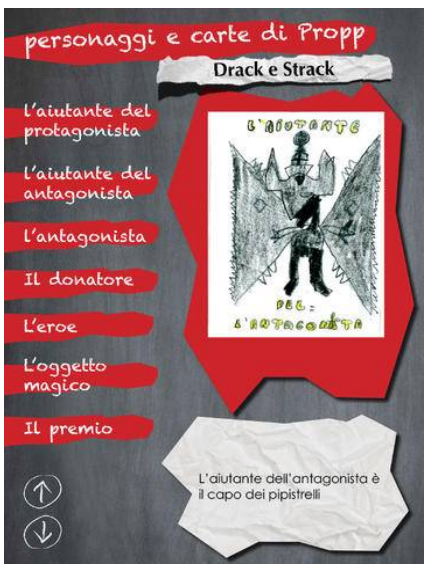

(c)

Figure 2. (a) Making photos for the app cover (b) App Cover (c) Propp Cards (iPad app).

Teachers note that although in this class the levels of learning and personal autonomy of pupils are very heterogeneous, they often observed actions of peer tutoring.

The four cases have allowed us to reflect on different themes: the relationship between technologies and the fruition of images, the link of photographs-activity, the virtuous circle that can be established between production and fruition to enhance authorship [23].

\subsection{Designing and Conducting a Lesson with Technologies}

The first variable we intend to consider is the availability of technology at school, not because it is more important than other one, but for the impact it can have on designing and conducting lesson.

In this sense, we affirm that the cases of "transmission" - according to instrumental approaches (T_I) and critical (T_C)-represent two experiences that we could define as antipodes.

In the T_I context, IWB have been installed in each class; it has been promoted natural and widespread use of technologies. Installing technology in a special lab, using it occasionally, is a risk and affects representations of the pupils about technology [8] (p. 38).

The teacher declares the importance of having full control over the entire iconic process of selfproduction for images for using them during class hours: it uses the camera to personally take photographs that will be object of analysis and discussion with students. She usually takes photos of 
the class engaged in various teaching activities and educational trips; she catches knows subjects in different moments or sets up functional photo-series asking for the collaboration of colleagues.

The teacher works with IWB daily, naturally, showing careful attention to creating the right conditions for enjoyment (obscuring the windows to lessen the overexposure of the projection) and scaffold pupils (moving the tool to height-child).

Overall and considering age, they move with familiarity. Children are asked to interact with photographs essentially through drag\&drop, constantly supporting the operations with verbalization, which is prompted by the teacher. Content numbers allow everyone to participate actively in the lesson.

Teacher used Smartboard Notebook to assemble the digital materials of the lessons (sets of photographs, optionally accompanied by captions written in print uppercase).

Every activity with the images started with verbalization and then drafting with some brief statements. The co-built material is then printed in color to be glued to the notebooks and is further enriched by the individual productions of children (texts, drawings).

\subsection{Pictures and Educational Activities}

Now we focus on what we mean about teaching with images, the special link of photography and activities and the virtuous circle that binds them. There are two possible scenarios created by the different weight given to the pictures (Figure 3):

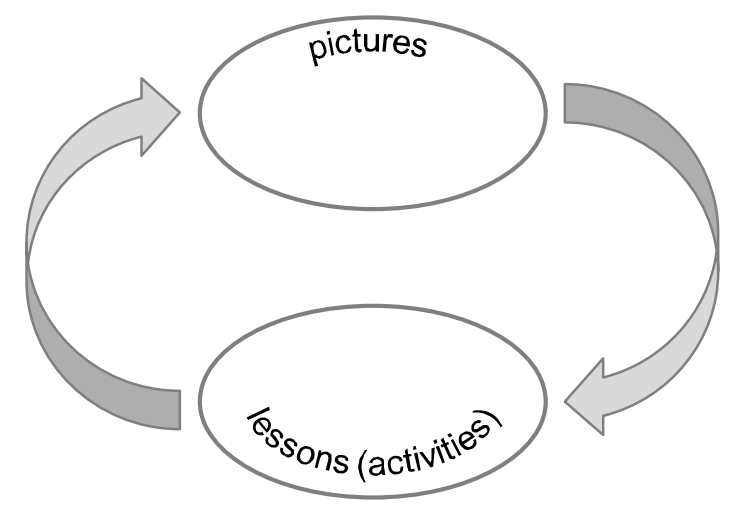

Figure 3. Pictures and educational activities.

- first scenario (from photographs to lessons-activity): in this case images play a critical role, without them the lesson could not take place. It implies that the teacher spends time to their accurate selection or self-production. Images are the starting point of one or more activities, individual or in group. The pupil does not just play a role as a passive recipient, but they are explicitly called to act on images;

- $\quad$ second scenario (from lessons-activities to photographs): the teacher imagines a lesson and, once designed, realizes that inserting some pictures may be somewhat useful, interesting, stimulating, clarifying.

The precious value of photographic images is to offer genuinely "ambiguous" problems to students, which can only be tackled by trying to formulate hypotheses. In a lesson, the C_I teacher adopts the image of living things growth - to be ordered sequentially-posing a problem that requires an Adaptive Decision Making strategy (ADM) [24], in which there isn't just one correct answer.

The success of the activity is well synthesized in a statement by the pupils: “We do not know for sure what the right sequence is. But we know for sure that time has passed". The children formulated four hypotheses, all possible, including one not foreseen by the teacher. What changes in sequences is the photograph chosen as the "starting point", which consequently affects the entire sequence (Figure 4). 


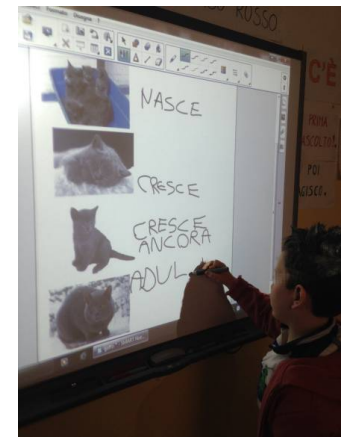

(a)

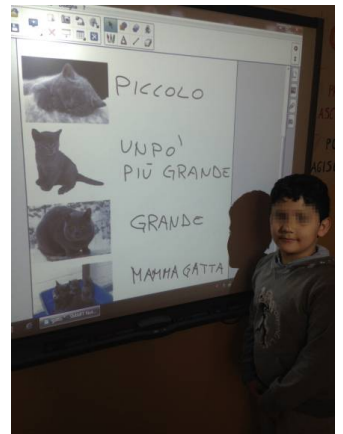

(b)

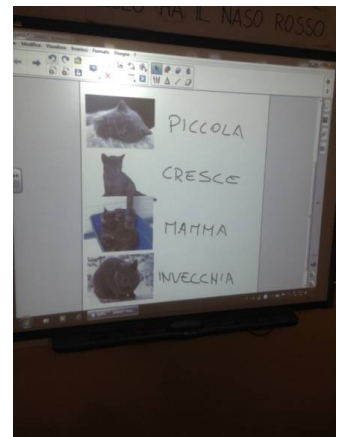

(c)

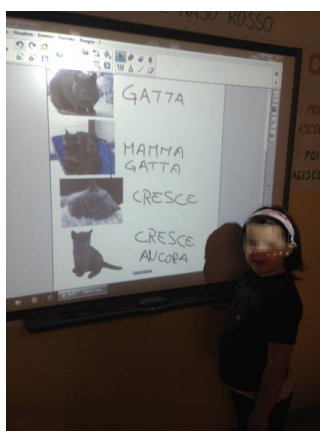

(d)

Figure 4. In the sequence (a-d), students order sequentially the pictures given.

\subsection{The Authorship: The Virtuous Circle of Making and Consuming}

The main feature of the cases in which the object of the study was the making of photographs is the role of author who is covered by the students.

In the M_C case, the child's involvement has been guaranteed throughout all stages of the work. The project, strongly backed and shared by the teaching staff and supported by an expert, took the form of an iPad app called "La fabbrica delle storie", available for free download for iOS devices. This is a modality of "generative multimedia documentation" [25].

In this fifth class, the photo lab-understood as experiential dimension that calls for action and thought on the action-helped teachers and pupils to conceive the image as a cultural product. The pupil used to go out on the territory, attendance of public places (exhibitions, theaters, museums), the presence of experts, the use of meta-cognitive methodologies for resolution of problematic situations. Photography takes on the form of object, endowed with its own dignity, to enjoy and appreciate; it is a way of approaching the world ("their third eye").

Noteworthy is the inclusive value given to the photographic practice: in the group, consisting of 19 pupils, 2 children have special needs. In the lab evaluation over the three-year course, they benefited from it, finding in the photography a privileged expressive channel and a sincere confrontation with their friends, perhaps less skilled in expressive-creative activity. Frequently, it has been observed situations of peer tutoring, in the sense of profitable integration of skills.

Although it does not require such a creative spirit, making shots in order to produce stories in stop motion has not resolved into mere execution: the complexity of the story characters movementsometimes more than one in the same scene-demanded to be simplified, decomposing it into smaller units of action. For example, in one of the observed sessions, a little girl moved objects, and the other took pictures. While occupying different roles, the student engaged with the camera provided valuable feedback to the companion. The view of the scene through the camera screen evidently gave her an idea of how the finished product could have been (Figure 5).

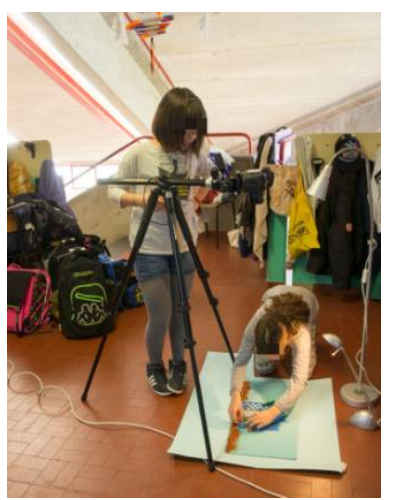

(a)

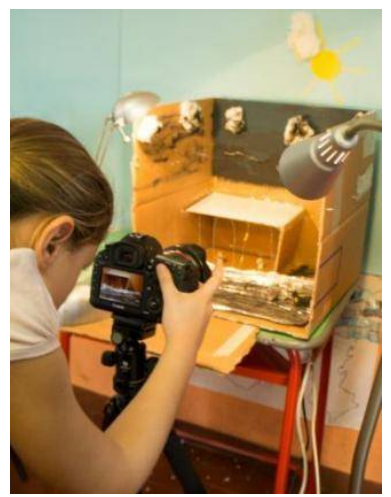

(b)

Figure 5. In the sequence $(\mathbf{a}, \mathbf{b})$, children are taking photos $\left(\mathrm{P}_{-} \mathrm{C}\right)$. 
We conclude with a reflection about the photographic gesture. The advent of the display, which gradually replaced the viewfinder until its complete elimination, seems to be the element that has led to the expansion of the possibilities of movement. In the traditional camera, in fact, the need to look in the viewfinder conditioned the photographer, also because of the habit of closing the eye not engaged in the photographic act.

With the visual display, the gesture changes radically; we take pictures with open eyes and the visual field opens up to include at the same time the small framed image (in reduced scale according to the display size) and the photographic object in its totality. Compared to the contact between the photographer's face and the device that the use of the optical viewfinder imposes, the display induces to look at a certain distance. The frame is inserted in a context far larger than the eye can catch through the viewfinder. In addition to this, unlike the viewfinder, the vision of the display is not exclusive to the photographer and this allows the choice of the frame opened to external contributions. Photography is transformed into such cases in a collaborative act in which anyone who accesses the view offered by the display can participate in the game with the spatial categories and thus contribute to determining the perspective of the shot [26]. It is precisely this evolution of photography in collaborative work - as suggested by the affordances of digital media with display - to be extremely interesting for teachers and on which to try to invest more, from a didactic point of view (Figure 6).

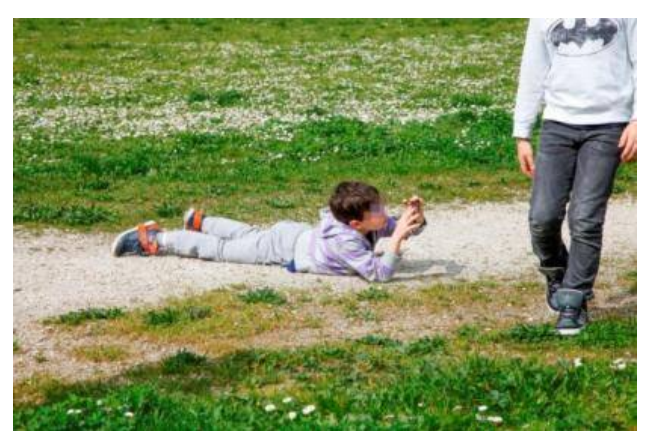

(a)

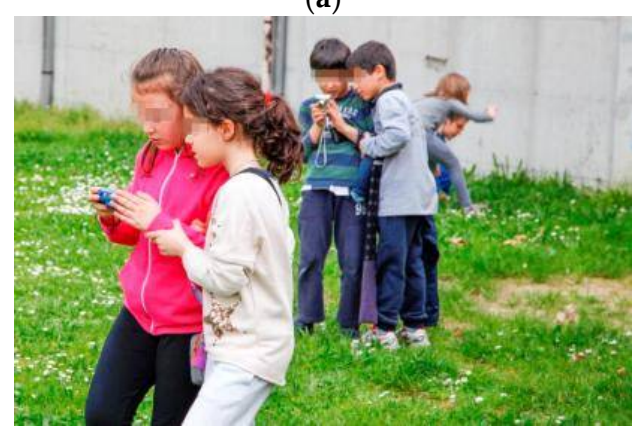

(c)

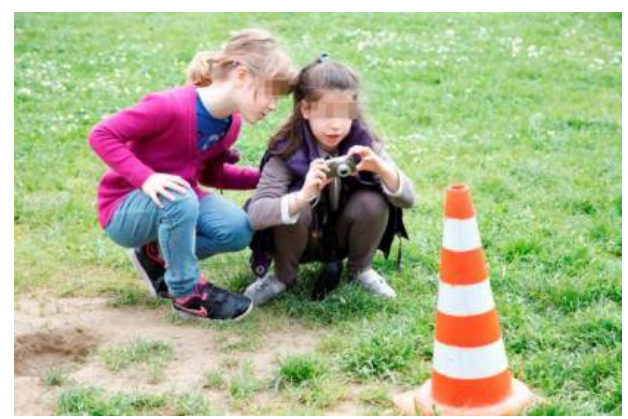

(b)

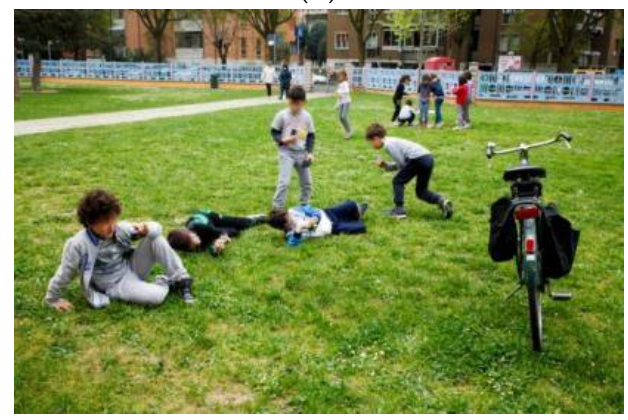

(d)

Figure 6. In the sequence $(\mathbf{a}-\mathrm{d})$, collaborative practices during a photographic session (M_I).

\section{Discussion}

Starting from the pedagogical reflections about the cases, we try to focus on what we mean about teaching with images. The question that leads us is the following: what tips may teachers need to know to be (more) aware about using photography in their activities without the need for or become specialized or experienced photographers?

We find it useful to make some guiding principles anchored to the three essential components of the teacher's activity (design, communication, evaluation).

Educational phases of teaching with images could be four (Figure 7). 


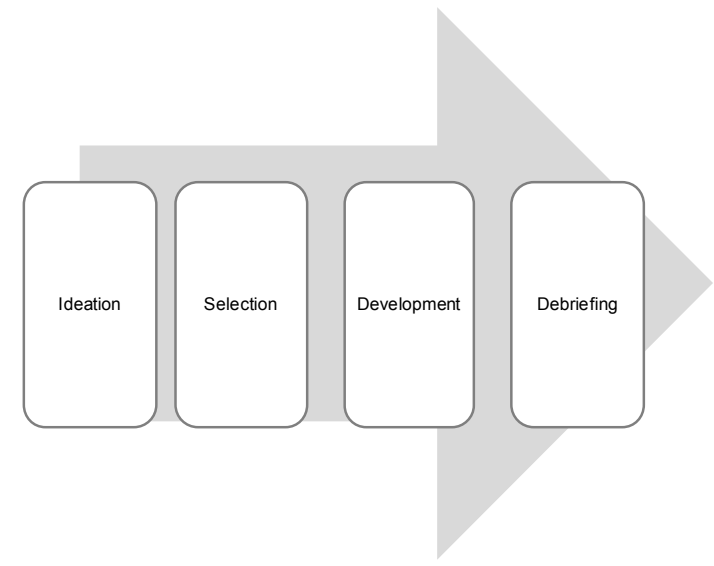

Figure 7. Educational phases of teaching with images.

First step is ideation: the teacher will refer to the National Guidelines for identifying skill targets; he will imagine a lesson plan that provides photographic images as essential materials for achieving the identified goals. In our conception of a didactics that is deliberately and intentionally based on the image, the moment of fruition is an opportunity to enhance the pupil by involving him in the process of meanings co-building. This is reason why we hope that the pupil-photography relationship is preferably inserted within a learning framework that involves the realization of a significant activity.

This could prevent two of the most common temptations to which you are exposed when you are going to design a lesson with the images:

- adopting pictures according to "the fallacious conception of the decorative utility of the image" on the basis of the illusion that "by introducing elements of visual pleasure students learn more" [3] (p. 27);

- using images more as a support for the teacher than to facilitate cognitive anchoring and learners' learning; this happens when one does not think about the psychological and communicative functions of the images [5] and adopt too complex pictures for the pupils' age or poorly in terms of quality. This risk is all the stronger when it comes up with the age of the learners and the "presentations" are for teachers the most common vehicle to "pass" the knowledge.

How can we make the pupils act on the pictures? There are three transitive verbs that we have identified:

- analyzing the photographs, in ways that range from free exploration to teacher-led analysis, using question-stimulus or synthetic check-lists, also in order to verify their understanding; embedded in more articulated inquiry-based paths, from including images in treasure hunt to webquest (photographs as investigation material);

- manipulating photographs according to various levels of complexity, i.e., by moving and comparing, textual or iconic annotations, cropping them to extrapolate a detail, framing them, completing them by captions, creating collages, up to the photo editing that involves contrast modification, brightness, saturation, application of filters (photographs as work objects);

- taking photographs or produce textual or multimedia artefacts based on them, photo-narratives or video (photographs as a stimulus to production).

As you can see, the three ways can be closely interconnected.

The second step is particularly delicate and is related to the choice of one or more images. It is necessary to take into account some of the criteria, partly from the Image Design (ID) [27] and adapted to our purpose:

- legibility: the satisfaction of this criterion, which refers to the technical quality of the image, constitutes the basis to allow access and enjoyment. There are two factors involved: the intrinsic 
qualities of the image, in relation to the ways in which it is made, and the technological support through which it will be conveyed;

- readability: this criterion deals with the content of the image and its ability to reach its recipients in an effective, unambiguous way. A possible strategy to "disambiguate" the image may be to present it simultaneously to its caption or to include graphic markers on it. Ambiguity might reside not in an image in itself, but in the relationship created (or asking the student to establish) between two or more images that make up a series. In our case, the ambiguity of the image (perceptual or semantic) could be exploited in an educational way;

- relevance: this criterion is the most exquisitely didactic one and asks the teacher to question about the significance of meaning attributed to the image in relation to the skill goal and the imagined activity.

The third stage is the activity: in principle, we suggest paying attention to two fundamental variables, namely space and time of fruition. Pupils should be put in the best conditions to access the images, to be able to watch them from far and near, to enlarge them, to manipulate them for enough time.

The last step is debriefing: in this delicate moment, the teacher will have to pull the line of the lesson in accordance with the strategy required to deal with the "problem" posed by the image.

Conflicts of Interest: The author declares no conflict of interest.

\section{References}

1. Damiano, E. La Mediazione Didattica: Per una Teoria Dell'insegnamento; Franco Angeli: Milano, Italy, 2013.

2. Shulman, S.L. Knowledge and Teaching: Foundations of the New Reform. Harvard Educ. Rev. 1987, 57, $1-21$.

3. Calvani, A. Principi Dell'istruzione e Strategie per Insegnare: Criteri per una Didattica Efficace; Carocci: Roma, Italy, 2011.

4. Paoletti, G. Comprendere Testi con Figure. Immagini, Diagrammi e Grafici nel Design per L'istruzione; Franco Angeli: Milano, Italy, 2011.

5. Clark, R.C.; Lyons, C. Graphics for Learning: Proven Guidelines for Planning, Designing, and Evaluating Visuals in Training Materials; Pfeiffer: San Francisco, CA, USA, 2010.

6. Mayer, R.E. Multimedia Learning; Cambridge University Press: New York, NY, USA, 2009.

7. Sweller, J.; Ayres, P.; Kalyuga, S. Cognitive Load Theory; Springer: New York, NY, USA, 2011.

8. Rivoltella, P.C.; Ferrari, S. A Scuola con i Media Digitali: Problemi, Didattiche, Strumenti; Vita e Pensiero: Milano, Italy, 2010.

9. Rivoltella, P.C.; Sinini, G. Apprendimenti Digitali? Una Sperimentazione nella Scuola Primaria; EDUCatt Università Cattolica: Milano, Italy, 2012.

10. Rivoltella, P.C. Neurodidattica: Insegnare al Cervello che Apprende; Raffaello Cortina: Milano, Italy, 2012.

11. Laurillard, D. Insegnamento Come Scienza Della Progettazione: Costruire Modelli Pedagogici per Apprendere con le Tecnologie; Franco Angeli: Milano, Italy, 2014.

12. Zeki, S. A Vision of the Brain; Blackwell Scientific: Oxford, UK, 1993.

13. Freedberg, D.; Gallese, V. Movimento, emozione ed empatia nell'esperienza estetica. In Teorie Dell'immagine: Il Dibattito Contemporaneo; Pinotti, A., Somaini, A., Eds.; Raffaello Cortina: Milano, Italy, 2009; pp. 331-351.

14. Zeki, S. Splendori e Miserie del Cervello; Codice Edizioni: Torino, Italy, 2010.

15. Gardner, H. Sapere per Comprendere. Discipline di Studio e Disciplina della Mente; Feltrinelli: Milano, Italy, 2009.

16. Damasio, A. L'errore di Cartesio: Emozione, Ragione e Cervello Umano; Adelphi: Milano, Italy, 2012.

17. Ritchin, F. Dopo la Fotografia; Einaudi, Torino, Italy, 2012.

18. Barthes, R. La Camera Chiara: Nota Sulla Fotografia; Einaudi, Torino, Italy, 2003.

19. Sontag, S. Sulla Fotografia; Einaudi: Torino, Italy, 2004.

20. Stake, R. E. The Art of Case Study Research; Sage Publications: Thousand Oaks, CA, USA, 1995.

21. Longobardi, L.; Boinnard, N. (Eds.) JIBS. The Global Online Marketplace for Educational Clips. Pilot Phase Results, 2004. Available online: http://goo.gl/HVZ4sN (accessed on 12 September 2017). 
22. Carenzio, A.; Cattaneo, A. L'uso degli audiovisivi. In Tecnologie, Formazione, Professioni. Idee e Tecniche per L'innovazione; Cattaneo, A., Rivoltella, P.C., Eds.; Unicopli: Milano, Italy, 2010; pp. 219-232.

23. Schürch, D. Psicodidattica della Fotografia nel Bambino dai 3 ai 7 anni. L'altro Sguardo Sull'ambiente di Vita; Franco Angeli: Milano, Italy, 2007.

24. Goldberg, E. Il Paradosso Della Saggezza: Come la Mente Diventa Più Forte Quando il Cervello Invecchia; TEA: Milano, Italy, 2012.

25. Torello, E. La documentazione generativa multimediale a scuola. Rivista Scuola IaD 2011, 3. Available online: http://goo.gl/9893yv (accessed on 12 September 2017).

26. Campanelli, V.; Cadioli, M. (Eds.) Snap Shooters. L'evoluzione del Gesto Fo-tografico; MAO (Media \& Arts Office Onlus): Napoli, Italy, 2012.

27. Pettersson, R. Information Design 3. Image Design. Wien: International Institute for Information Design (IIID), 2015. Available online: http://goo.gl/HGbSOg (accessed on 12 September 2017).

(C) 2017 by the authors. Licensee MDPI, Basel, Switzerland. This article is an open access article distributed under the terms and conditions of the Creative Commons Attribution (CC BY) license (http://creativecommons.org/licenses/by/4.0/). 